\title{
Research on Algorithm of Sea Oily Soil Removal Technology of Intelligent Analysis and Recognition Based on Vague Set
}

\author{
Kun Zhang ${ }^{1,2,3,4, a}$,Chong Shen ${ }^{1,3, b^{*}}$, Haifeng Wang ${ }^{2,4, c}$ and Zhuang $\mathrm{Li}^{2,4, \mathrm{~d}}$ \\ ${ }^{1}$ State Key Laboratory of Marine Resources Utilization in South China Sea, Hainan University, \\ Haikou, Hainan, 570228, China \\ ${ }^{2}$ College of Ocean Information Engineering, Hainan Tropical Ocean University, Sanya, Hainan, \\ 572022, China \\ ${ }^{3}$ College of Information Science and Technology, Hainan University, Haikou, Hainan, 570228, \\ China \\ ${ }^{4}$ Sanya Key Laboratory of Computer Visiono, Hainan Tropical Ocean University, Sanya, Hainan, \\ 572022, China \\ azk0588@163.com, "bchongshen@hainu.edu.cn, wyfxxz@163.com, ${ }^{\mathrm{d}}$ hitlz@163.com \\ "The corresponding author
}

Keywords: Vague Set; Intelligent Analysis; Image Processing; Similarity Measure; Priority

\begin{abstract}
A high resolution camera was suggested to be installed above oily soil extractor to recognize the oily soil on sea surface, which then was subjected to image processing to get data. The Vague water quality assessment method based on similarity measures between Vague sets would be applied to assess the water quality of the seawater polluted by oily soil. Three different regions in the simulated seawater polluted area was selected for water quality assessment and the objects to be collected with priority was determined, then the SCM was used to control the oily soil collector in front of oil storage ship to collect oily soil in motion, so as to quickly remove sea oily soil intelligently.
\end{abstract}

\section{Introduction}

Currently, there are growing severity in oil pollution at sea and huge pollution to the ocean environment by misoperation in exploration and prospecting of offshore field, various accidents, such as famous Gulfian oil leakage, 7.16 accident in Dalian newport, latest Penglai 19-3 oil field leakage, as well as recurrent ship oil leakage, especially the frequent collision of oil tankers. In Sanya, a typical island terrain facing sea on all sides, including South China Sea, the surrounding ocean environment plays a vital role for the life status on Hainan island. Rapid and efficient depollution is of crucial importance while oil leak accidents breaks out in today when ocean oil pollution is increasingly severe. For the moment, there are mainly two kinds of good machinery and methods for collecting ocean oily soil in China: one is to leave a gap on shipboard in the front of oil collecting ship to channel directly the oily soil into the ship for collection; another is to use cleaner composed of buoy, motor, roller housing, transmission shaft, hub, brush holder, brush finish and cleaner and oil trap.

Comparatively speaking, the first method pollutes the ship. As oily soil disperses towards two sides due to the driving force of wave when the ship advances, cleaning is slow and not thorough. While the second method has very slow speed as the strongly adhesive oily soil attached to cleaner must be removed before working long. The intelligent and quick ocean oily soil removal system developed by this project installed a high resolution camera to recognize the oily soil on sea surface, got data after image processing, and then the SCM controlled the oily soil collector in the front of oil storage ship to collect oily soil in motion to be transported via hose to oil pump and to be pumped to oil separator on oil storage ship, lastly the oil and 
water were separated. This method improves the traditional oil collecting device, and significantly raises oil collection efficiency.

\section{Composition of Front System of Ship}

To prevent oily soil from further expanding after oil leaks, first enclosed oily soil surface with rubber to prevent the pollution from expanding, then the pump took in oily soil to quickly remove oily soil. This oily soil scavenging system is mainly composed of oily soil collector and oily soil catching vessel. Above the oily soil extractor was installed a high resolution camera to capture the digital image on sea surface in real time to be transmitted to master control computer on oily soil catching vessel, and the master control computer processes and analyzes the image. The computer controlled the movement direction and forward velocity of oily soil extractor in the front of oil storage ship according to analytic result, analyzed water-quality indices collected by image via algorithm to figure out the relatively most severely polluted region (such as in terms of concentration and thickness, etc.) to absorb it intelligently with priority, then the oily soil was transported to oil storage ship via hose and pump for oil and water separation. The system structure is as shown in Fig. 1.

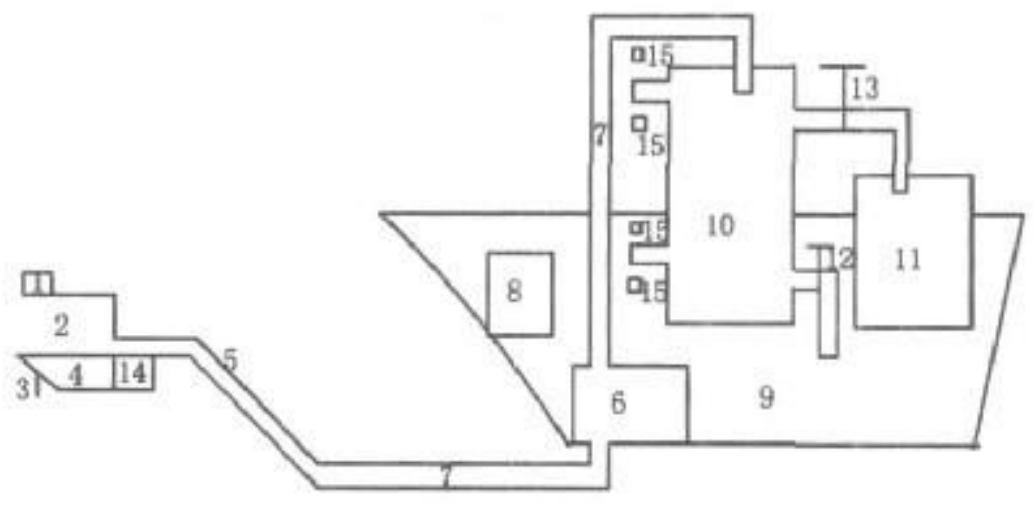

Figure 1. System structure

Note: 1.Camera; 2. Suction inlet; 3. Steering device; 4.Buoyancy tank; 5. Oil hose; 6. Oil pump; 7. Hard oil pipe; 8. Control circuit board and computer; 9. Hull; 10. Oil container; 11. Oil drum; 12. Water outlet electromagnetic valve; 13. Oil out electromagnetic valve; 14. Airscrew; 15. Photoelectric detector.

\section{Research on Intelligent Analytical Algorithm}

According to the pollution degree of seawater by oily soil, adopted the method of water quality analysis for processing, prejudged the selection of intelligent oil collection. For the problem of water quality assessment, as the sample of water source has no strict property, it has uncertain shape and categories. People always endlessly pursue better theories and methods of researching uncertain information. The Vague set theory, raised by Gao and Buehrer in 1993, is generalization of fuzzy set theory. So far, the methods of Vague set theory have been raised and applied to solve a lot of practical problems. For example, Vague set pattern recognition method, Vague set TOPSIS scheme optimization, Vague set fault diagnosis method, etc., which, of course, have relative merits. The largest merit of this theory is the uncertainty of uncertain information is directly reflected in Vague value. The paper applied it to Vague water quality assessment method based on similarity measure between Vague sets, assessed water quality for the seawater polluted by oily soil, and researched and selected three different regions in the seawater polluted area for water quality assessment. 


\section{Concept of Vague Set}

Set as domain of discourse, Vague set on $X$ is described by true membership function $t_{A}$ and false membership function $f_{A} t_{A}: X \rightarrow[0,1], f_{A}: X \rightarrow[0,1]$. Where for any $x \in X, t_{A}(x)+f_{A}(x) \leq 1 t_{A}(x)$ is the lower boundary of positive membership degree derived by the evidence supporting $x, f_{A}(x)$ is the lower boundary of negative membership degree derived by the evidence against $x$. The membership degree of element $x$ in Vague set $A$ is defined by a sub-range ${ }^{\left[t_{A}(x), 1-f_{A}(x)\right]}$ of range ${ }^{[0,1]}$, call this range as Vague value of element $x$ in $A$, note it as $A(x)=\left[t_{A}(x), 1-f_{A}(x)\right]$, or $x=\left[t_{x}, 1-f_{x}\right]$. Call $t_{x}$ as positivity of $x$ against Vague set $A, f_{x}$ as negativity of $x$ against Vague set $A, \pi_{x}=1-t_{x}-f_{x}$ as uncertainty of $x$ against Vague set $A, S_{x}=t_{x}-f_{x}$ as core of $x$ against Vague $\operatorname{set} A$.

When $X=\left\{x_{1}, x_{2}, \mathrm{~L}, x_{n}\right\}$ is discrete domain of discourse, note Vague set $A$ as

$$
\begin{aligned}
A=\{ & {\left[t_{A}\left(x_{1}\right), 1-f_{A}\left(x_{1}\right)\right],\left[t_{A}\left(x_{2}\right), 1-f_{A}\left(x_{2}\right)\right], } \\
& \left.\mathrm{L},\left[t_{A}\left(x_{n}\right), 1-f_{A}\left(x_{n}\right)\right]\right\} .
\end{aligned}
$$

\section{A Kind of Data Mining of Vague Value}

Definition $1[8]$ sets $x=\left[t_{x}, 1-f_{x}\right]$ as Vague value, a data mining method for it is:

Define

$t_{x}^{(0)}=t_{x}, f_{x}^{(0)}=f_{x} . \pi_{x}^{(0)}=\pi_{x} ; t_{x}^{(m)}=t_{x}\left(1+\pi_{x}+\pi_{x}^{2}+\mathrm{L}+\pi_{x}^{m}\right), f_{x}^{(m)}=f_{x}\left(1+\pi_{x}+\mathrm{L}+\pi_{x}^{m}\right), \pi_{x}^{(m)}=\pi_{x}^{m+1}$, $m=1,2, \mathrm{~L}$

Theorem 1[8] $x_{x}^{(m)}=\left[t_{x}^{(m)}, 1-f_{x}^{(m)}\right](m=0,1,2, \mathrm{~L} \cdot)$ is Vague value.

\section{New Similarity Measure of Vague Set}

The similarity measure of Vague set has always been a hotspot of research in recent years, as shown in literature [14], [15] and [16]. The paper further suggested a new method.

Definition 2 Set domain of discourse $X=\left\{x_{1}, x_{2}, \mathrm{~L}, x_{n}\right\}$, on which there is Vague set,

$B=\left(\left[t_{B}\left(x_{1}\right), 1-f_{B}\left(x_{1}\right)\right],\left[t_{B}\left(x_{2}\right), 1-f_{B}\left(x_{2}\right)\right]\right.$,

$$
\left.\mathrm{L},\left[t_{B}\left(x_{n}\right), 1-f_{B}\left(x_{n}\right)\right]\right) \text {, }
$$

Note simply as following respectively:

$$
\begin{aligned}
& A=\left(\left[t_{x 1}, 1-f_{x 1}\right],\left[t_{x 2}, 1-f_{x 2}\right], \mathrm{L},\left[t_{x n}, 1-f_{x n}\right]\right), \\
& B=\left(\left[t_{y 1}, 1-f_{y 1}\right], \mathrm{L},\left[t_{y n}, 1-f_{y n}\right]\right),
\end{aligned}
$$

If formula $M(A, B)$ meets following theorem, then formula $M(A, B)$ is called similarity measure between Vague sets $\mathrm{A}$ and $\mathrm{B}$.

(A1) $0 \leq M(A, B) \leq 1$;

(A2) $M(A, B)=M(B, A)$;

(A3) $A=\{[0,0], \mathrm{L},[0,0]\}, B=\{[1,1], \mathrm{L},[1,1]\}$ or $A=\{[1,1], \mathrm{L},[1,1]\}$,

When $B=\{[0,0], \mathrm{L},[0,0]\}, M(A, B)=0$;

(A4) $M(A, B)=1 \Leftrightarrow A=B, \pi_{x i}=\pi_{y i}=0,(i=1,2, \mathrm{~L}, n)$. 
This definition highlights a characteristic, i.e. emphasizing uncertainty, to be specific: condition of (A4) $A=B, \pi_{x i}=\pi_{y i}=0$.

Theorem 2, then following formula $M^{(m)}(A, B)$ is similarity measure between Vague sets A and B $(m=0,1,2, \mathrm{~L}$.$) :$

$$
M^{(m)}(A, B)=\frac{1}{n} \sum_{I=1}^{n}\left(1-\frac{\left|S_{x i}^{(m)}-S_{y i}^{(m)}\right|+\left|\pi_{x i}^{(m)}-\pi_{y i}^{(m)}\right|}{2}\right) \mathrm{g}\left(1-\frac{\left|t_{x i}^{(m)}-t_{y i}^{(m)}\right|+\left|f_{x i}^{(m)}-f_{y i}^{(m)}\right|+\pi_{x}^{(m)}+\pi_{y i}^{(m)}}{2}\right)
$$

With different parameters $m$, different similarity measures between Vague sets A and B can be obtained.

\section{Water Quality Assessment Method Based on Similarity Measure between Vague Sets}

A lot of literature presents Vague set pattern recognition method based on similarity measure, such as literature [4] and [11]. This paper applied Vague set pattern recognition method based on similarity measure for the problem of water quality assessment.

The concrete application steps for Vague set pattern recognition method based on similarity measure are as follows: step 1, establishing index set $X=\left\{x_{1}, x_{2}, \mathrm{~L}, x_{n}\right\}$; step 2, establishing standard sample set $A=\left\{A_{1}, A_{2}, \mathrm{~L}, A_{k}\right\}$ on index set and establish to-be-assessed sample set $B=\left\{B_{1}, B_{2}, \mathrm{~L}, B_{h}\right\}$, providing raw data; step 3, entering Vague environment, .i.e. translating raw data into Vague set data; step 4, calculating the similarity measure between Vague set of to-be-assessed sample $B_{j}(j=1,2, \mathrm{~L}, h)$ and Vague set of standard sample $A_{i}(i=1,2, \mathrm{~L}, k)$; step 5, Vague set pattern recognition. If the value of similarity measure is sequenced as follows:

$M\left(B_{j}, A_{i_{1}}\right) \geq M\left(B_{j}, A_{i_{2}}\right) \geq \mathrm{L} \geq M\left(B_{j}, A_{i_{k}}\right)$, Then the to-be-assessed sample ${ }_{j}$ belongs to standard sample ${ }^{A_{i_{1}}}$, where $i_{1} i_{2} \mathrm{~L} i_{k}$ is a non-repetitive full array of $1,2, \mathrm{~L}, k$.

\section{Application Cases}

Applied national standard as standard sample, selected the monitoring data of three sample regions with oil spilling as to-be-assessed sample, used Vague set pattern recognition method based on similarity measure for recognition assessment, with concrete practice as follows.

Established Index Set. Established index set, here the first level factor was taken for example, took $X=\left\{x_{1}, x_{2}, x_{3}, x_{4}\right\}$, where $x_{1}$ is hydrocarbon compound, $x_{2}$ is colloid, $x_{3}$ is asphaltene, $x_{4}$ is soluble paraffin, which are part of indices of national standard.

Establish To-be-assessed Sample Set and Standard Sample Set. Established standard sample set $A=\left\{A_{1}, A_{2}, A_{3}, A_{4}, A_{5}\right\}$ on index set, where the water quality $A_{1}$ is category I, $A_{2}$ is category II, $A_{3}$ is category III, $A_{4}$ is category IV, $A_{5}$ is category V, which correspond to pollution degrees of extremely light, light, medium, heavy pollution, and grave pollution respectively.

Established to-be-assessed sample set $B=\left\{B_{1}, B_{2}, B_{3}\right\}$ on index set, where $B_{1}$ is region sampling point 1 , $B_{2}$ is region sampling point $2, B_{3}$ is region sampling point 3 .

Enter Vague Environment. Entering Vague environment means translating raw data into Vague value data. The literature [9] presents the formula translating non-negative single value data into Vague value data, which takes the following form in this case: 


$$
x_{i j}=\left[t_{i j}, 1-f_{i j}\right]=\left(\frac{x_{i j}}{x_{i \max }}, 1-\left(\frac{x_{i j}}{x_{i \max }}\right)^{\frac{1}{2}}\right)
$$

Where $x_{j \max }=\max \left\{x_{1 j}, x_{2 j}, \mathrm{~L}, x_{8 j}\right\}, j=1,2,3,4,5$.

Applied formula (2) to translate the collected raw data into Vague value data to get Vague value data of standard sample and to-be-assessed sample.

Calculate the Distance between Vague Set For to-be-assessed Sample and Vague Set for Standard Sample. Applied formula (1), took parameter $m=2$, calculated the similarity measure between Vague set of to-be-assessed sample $B_{j}(j=1,2,3)$ and Vague set of standard sample $A_{i}(i=1,2,3,4,5)$ to get the result and the magnitude relation and figure out the rank to form priority relation.

\section{Summary}

The above Vague set pattern recognition method based on similarity measure, which obtains the data of the sampling point of three oil spilling sample regions after image processing, was used to research water quality assessment problem and provided a new method and reference for research on the like problems. This method is a Vague set pattern recognition method based on new Vague set similarity measure (1), combines the result from data with composite factors of oil layer density of oil spilling sea area, and feeds the result back to processor terminal to give instruction as to which direction and region should be collected with priority, hence forming a quick sea oily soil removal technology based on intelligent analysis and intelligent recognition, which is of certain popularization and socioeconomic value.

\section{Acknowledgement}

This research was financially supported by the National Natural Science Foundation of China (No. 61461017); the Hainan Natural Science Foundation Innovation Research Team Project (Research on Indoor Precision Real - time Location System Based on Ultra - wideband); the Scientific and Technological Cooperative Project for College and Region of Sanya (No.2013YD36); the Key Laboratory of Sanya Project (No.L1410).

\section{References}

[1] Weihua Cai, Le Ma, Hua Wang, Zhuo Huang, The Numerical Simulation Model of Ship Navigation, Computer Applications and Software, Vol.29, No.02, pp.192-196+236, 2012.

[2] Jiaxuan Li, Zeming Shi, Lin Zheng, Shijun Ni. Evaluation on Potential Ecological Risk of Heavy Metals Pollution in Sediments from Tuojiang Drainage, Earth and Environment, Vol.38, No.04, pp.481-487, 2010.

[3] Huifang Feng, Qiufang He, Shiyou Xie, Jianfeng WANG, Evaluation and Analysis of the Rural Drinking Water Quality in Chongqing Karts Mountainous Regions, Earth and Environment, Vol.38, No.01, pp.54-58, 2010.

[4] Xinyu Zhang, Baodong Xin, Xiaohong Wang, etc, Progress in Research on Groundwater Pollution in Our Country, Earth and Environment, Vol.39, No.03, pp.415-422, 2011.

[5] Gao W L, Buehrer D J, Vague Sets, IEEE. Tran. Syst. Man. Cybern, Vol.23, No.02, pp.610-614, 1993. 
[6] Hongxu Wang, Fujin Zhang, Yunsheng Xu, Vague Weghted Decision-making Method and Its Application in Sugarcane Breeding, Computer and Computing Technologies in Agriculture V-5th IFIP TC 5/SIG 5.1 Conterence CCTA 2011, Proceedings, pp.85-91, 2011.

[7] Fang Yu, Application of TOPSIS Based on Vague Sets in the Scheme Evaluation, Mathematics in Practice and Theory, Vol.41, No.15, pp.178-183, 2011.

[8] Jun Ye, Research on Fault Diagnosis of Turbine Based on Similarity Measures Between Vague Sets, Proceedings of the CSEE, Vol.26, No.01, pp.16-20, 2006.

[9] Yongkai An, Yutong Zheng, Yongdong Wu, Tian Tian. Water Quality Evaluation of Landscape Water and Analysis on Remediable Countermeasures in Changchun City, Chinese environmental management (The album), No.06 pp.34-37, 2011.

[10] The State Environmental Protection Administration, The State Administration of quality supervision, inspection and quarantine. Environmental quality standards for surface water (GB3838-2002) [S] . Beijing: China environmental press, 2002.

[11] Hongxu Wang, Fujin Zhang, Xiaofang Fu. An Optimization Method Based on Vague Set Selection Architectural Engineering, 2012 International Conference on Industrial Control and Electronics Engineering, pp. 1254 - 1257, 2012.

[12] Kun Zhang, HongXu Wang, HaiFeng Wang, Zhuang Li, New Exploration on Definition of Similarity Measures Between Vague Sets, Journal of Natural Science of Heilongjiang University, Vol.29, No.03, pp.412-415, 2012.

[13] Kun Zhang, HongXu Wang, HaiFeng Wang, Zhuang Li, Vague Spatial Decision Method and Its an Application for the Location of Tailings Dam, Computer Science, Vol.41, No.04, pp.260-262, 2014.

[14] Kun ZHANG, HongXu WANG, HaiFeng WANG, Zhuang LI, Park Water Quality Evaluation Method Based on Similarity Measures between Vague Sets, Computer Engineering \& Software, Vol.35, No.02, pp.52-54, 2014.

[15] HaiFeng Wang, Kun Zhang, Zhuang Li, HongXu Wang, The Algorithm for Evaluation of Landscape Water Quality based on Intuitionistic Fuzzy sets of Emphasizing Hesitancy Degree, Advances in Eengineering Systems Research, vol.60, pp.1844-1848, 2016.

[16] Guangqiang Liu, Hong Geng, Guangbao Shi, Study on the Method of Oil Spill Removal, China Water Transport, Vol.10, No.02, pp.32-33, 2010.

[17] Tongshu Zhang, Dewen Zhang, Liangcheng Ren, Comparison of Ship - borne Oil Spill Recovery System at Home and Abroad, China Water Transport, Vol.09, No.02, pp.7-9, 2009.

[18] Yunfei Zhou, Dewen Zhang, Lei Chen, Peng Zhang, Design Improvement and Performance Test of Ship Side Oil Spill Recovery System, Journal of Wuhan University of Technology(Transportation Science \& Engineering), Vol.40, No.02, pp.285-288, 2016. 